\title{
UM CONCEITO FORTE DE TERCEIRO SETOR À LUZ DA TRADIÇÃO
}

\author{
ASSOCIATIVA
}

\section{A STRONG CONCEPT OF THE THIRD SECTOR IN THE LIGHT OF ASSOCIATIVE TRADITION}

\section{Eliane Fontana}

Doutora em Direito pela Universidade de Santa Cruz do Sul. Professora da Universidade do Vale do Taquari - UNIVATES. Docente do Curso de Direito. Advogada

\section{João Pedro Schmidt}

Doutor em Ciência Política pela Universidade Federal do Rio Grande do Sul, pósdoutorado pela The George Washinton University, Washington DC, Estados Unidos. Professor da Universidade de Santa Cruz do Sul - UNISC. Docente do Programa de Pós-Graduação em Direito.

\section{Resumo}

O terceiro setor - entendido como conjunto das organizações da sociedade civil, e não como conjunto de entidades sem fins lucrativos - expressa duas características humanas fundamentais: a cooperação e o altruísmo. Voltadas à solução de problemas públicos ou coletivos, as organizações sociais cumprem uma função sociopolítica de grande relevância. A compreensão dessa importância tem sido prejudicada pela prevalência, na literatura e no senso comum, de um conceito fraco de terceiro setor, erguido sobre a experiência histórica do nonprofit sector norte-americano, que põe em primeiro plano o caráter não lucrativo e filantrópico das organizações sociais. Esse conceito fraco é próprio da tradição filantrópica e filia-se à visão econômica liberal neoclássica, que atribui às organizações da sociedade civil a função residual de preencher falhas do mercado e do Estado. Afirmase aqui a pertinência política de um conceito forte de terceiro setor, assentado na tradição associativa e que põe em primeiro plano a capacidade cooperativa e associativa presente em todas as sociedades, devendo esse segmento ser compreendido como um setor específico, próprio da comunidade (sociedade civil), distinto do setor público e do privado. O método é histórico-crítico e a técnica de pesquisa é bibliográfica.

Palavras-chave: Altruísmo. Cooperação. Dicotomia público/privado. 
Setor não lucrativo. Terceiro setor.

\begin{abstract}
The third sector - defined as a group of civil society organizations, and not as a group of non-profit organizations - expresses two fundamental human characteristics: cooperation and altruism. Aimed at solving public or collective problems, social organizations fulfill a socio-political function of great relevance. The understanding of this importance has been hindered by the prevalence, in literature and in common sense, of a weak concept of the third sector, built on the historical experience of the North American nonprofit sector, which puts in the foreground the non-profit and philanthropic character of social organizations. This weak concept is characteristic of the philanthropic tradition and is affiliated to the neoclassical liberal economic vision, which attributes to civil society organizations the residual function of filling market and state failures. The political relevance of a strong concept of the third sector, based on the associative tradition and which puts in the foreground the cooperative and associative capacity present in all societies, is affirmed here, and this segment must be understood as a specific sector, proper to the community (civil society), distinct from the public and private sectors. The method is historical-critical and the research technique is bibliographic.
\end{abstract}

Key-words: Altruism. Cooperation. Non-profit sector. Public/private dichotomy. Third sector.

\title{
1. CONSIDERAÇÕES INICIAIS
}

O termo terceiro setor passou a ser utilizado com frequência nos círculos acadêmicos e políticos brasileiros especialmente a partir da década de 1980, para dar conta de um fenômeno novo naqueles anos: a expansão das organizações nãogovernamentais - ONGs. Décadas depois, o conceito ainda não está consolidado. Cercado de polêmicas, continua a enfrentar a concorrência de outros termos, como setor não lucrativo, setor filantrópico, setor do voluntariado, setor da sociedade civil, economia social e economia solidária. Por sua vez, cada um deles também sofre restrições, nenhum obtendo unanimidade entre intelectuais, agentes sociais e políticos.

Não se trata de gastar energias com uma discussão diletante sobre porque preferir umas palavras a outras. O furo é mais embaixo. A escolha terminológica reflete a compreensão acerca do papel sociopolítico das organizações da sociedade civil e a sua relação com o Estado e com o mercado. As polêmicas por detrás das palavras revelam diferentes concepções econômicas e políticas, cujos principais aspectos convém aclarar. Preliminarmente, cabe situar o tema no contexto do 
capitalismo do final do século XX e início do século XXI, e das visões econômicas e políticas hegemônicas: a economia neoclássica e o liberalismo.

Como o tema do terceiro setor se encaixa na concepção econômica hoje dominante, a economia neoclássica ou liberalismo econômico? O fundamento dessa visão é o homo economicus, cujas premissas foram assentadas por Adam Smith, sumarizadas na ideia de que os indivíduos são naturalmente egoístas, interessados em maximizar seu auto-interesse; o sistema que melhor se adapta à índole egoísta dos humanos é o livre mercado e a organização mais adequada para assegurar a eficiência econômica é a empresa privada. Em condições ótimas de informação e transparência, o livre mercado possibilita o atendimento dos interesses comuns com base na concorrência de agentes e empresas focados unicamente no seu próprio interesse, cabendo ao Estado basicamente o papel de assegurar as regras do jogo econômico, com um mínimo de intervenção. Todavia, o reconhecimento de que em parte alguma existiram ou existem as condições ótimas de livre concorrência levou diversos economistas neoclássicos à noção das falhas de mercado e de Estado, falhas que poderiam ser supridas por organizações não mercantis. Assim, sem fugir dos parâmetros gerais do homo economicus, a econômica neoclássica abre um espaço ao terceiro setor, confere-lhe um papel residual, o de sanar falhas do mercado e do Estado.

A economia neoclássica não reina absoluta no âmbito das ideias econômicas. A versão radicalizada do liberalismo econômico, o neoliberalismo, tem como contraparte um importante conjunto de economistas que exaltam o indispensável papel do Estado na economia de mercado, apoiados nas sólidas construções teóricas de Keynes, Polanyi, Myrdal e outros. Defensores do Estado de Bem-Estar Social (welfare state) argumentam que, além da indispensável regulação da economia, os aparelhos estatais assumiram ao longo do século $X X$ funções inéditas no atendimento de necessidades comuns à sociedade mediante sistemas públicos de educação, saúde e proteção social, que não podem ser cumpridas pela iniciativa privada. Neoliberais entendem que o intervencionismo estatal foi exagerado e prejudicial para o funcionamento do mercado, cabendo uma redução significativa da presença do Estado na forma de desregulamentações e privatizações. Se welfaristas e neoliberais discordam acerca do papel e da relação entre os domínios do Estado e do mercado, em grande parte compartilham a noção de que essas duas são as esferas básicas da vida social, e que ao terceiro setor cabe um papel residual na prestação de serviços 
públicos.

As fragilidades da economia neoclássica para explicar a dinâmica social e econômica das sociedades capitalistas às vésperas da $4^{a}$ revolução industrial, bem como as limitações do neoliberalismo e do welfarismo clássico, vêm sendo reconhecidas por toda parte. Desde a virada do século está aberta uma verdadeira "temporada de caça" a novas perspectivas políticas e econômicas, a teorias capazes de dar conta de fenômenos inéditos vinculados à globalização, à internet e às novas tecnologias, e apontar um rumo que seja sustentável do ponto de vista socioambiental.

O tema do terceiro setor pode ser melhor enfrentado quando se revisita o entendimento sobre quais são as esferas, os âmbitos da vida social. Seriam Estado e mercado as esferas fundamentais e únicas da vida social contemporânea? A resposta dos comunitaristas e de certos teóricos da sociedade civil é: não! Compreende-se melhor os fenômenos e dinâmicas sociais à luz de três esferas: Estado, comunidade (ou estado civil) e mercado. Amitai Etzioni (2001) afirma que cada uma dessas esferas tem suas fortalezas e fraquezas, que nenhuma tem condições de atender com eficácia e eficiência todas as necessidades da sociedade, de modo que o equilíbrio e a complementaridade entre as mesmas é o melhor caminho. Teóricos da sociedade civil, como Benjamin Barber (2000) e Andrew Arato e Jean Cohen (2000), consideram esta esfera como distinta do Estado e do mercado. Autores da economia social e solidária reforçam a necessidade de romper o dualismo Estado/mercado predominante, em nome da visão de que a economia é mais que mercado e a política é mais que Estado. (LAVILLE, 2015)

O conceito de terceiro setor está diretamente relacionado a essa compreensão das esferas sociais e da importância conferida a cada qual. O problema que conduz o presente texto leva em conta que o conceito fraco de terceiro setor, associado à visão neoclássica e também às teorias convencionais do welfare state, implica na admissão de que às organizações sociais competem apenas funções residuais. A interrogação aqui posta vai em sentido diverso: quais são os requisitos para a construção de um conceito forte de terceiro setor?

A resposta é dada em quatro momentos. Inicialmente é apresentada uma breve trajetória do conceito de terceiro setor e a sua fragilidade por estar associada à tradição filantrópica. A seguir, são elencados rótulos alternativos para denominar as organizações sociais, com as vantagens e desvantagens de cada qual. Adiante, propõe-se uma releitura do terceiro setor à luz da tradição associativa, ressaltando 
que a cooperação é a sua base principal e o altruísmo é um elemento importante, mas complementar. Por derradeiro, o conceito forte de terceiro setor é detalhado, com indicação de seus enlaces teóricos. O método de abordagem é histórico-crítico e a técnica de pesquisa é bibliográfica.

\section{O CONCEITO FRACO DE TERCEIRO SETOR: A TRAJETÓRIA DO NOPROFIT SECTOR}

A expressão terceiro setor foi formulada nos anos 1970, nos Estados Unidos. Até então, o amplo leque das organizações sociais e religiosas não eram consideradas um bloco e nem existia a ideia de que formassem um setor. Para realçar o descompasso histórico entre a historicidade das organizações sociais e a do conceito, cabe lembrar que os Estados Unidos abrigaram desde os primórdios da colonização, no século XVII, um amplo leque de comunidades locais e que no século seguinte estruturaram-se organizações influentes. No ano de 1727, Benjamin Franklin criou o famoso "Junto Club", arquétipo do nascente associativismo: auto-governado, filantrópico e voltado ao bem comum. (SIEVERS, 2010) Organizações como a maçonaria tiveram importante participação na Independência do país (1776). O associativismo cresceu rapidamente ao longo do século XIX e nas primeiras décadas do século $X X$. Na segunda metade do século XIX e nas primeiras décadas do século XX desenvolveu-se a notável experiência mutualista das sociedades fraternas. Organizadas sob o princípio da autoajuda e da reciprocidade, as sociedades constituíram um vasto leque de unidades locais (lodges), democraticamente geridas, voltadas à provisão de auxílio-doença, auxílio funeral e seguro de vida. Com o tempo, algumas sociedades criaram orfanatos, casas de atenção aos idosos e uma rede de atenção à saúde. Trabalhadores e pobres associaram-se massivamente ao fraternalismo. Um levantamento na década de 1920 indicou que um em cada três adultos homens era membro de uma sociedade fraterna, o equivalente a uns 30-35 milhões de associados. Por cerca de um século o fraternalismo congregou mais americanos que qualquer outra organização, à exceção das igrejas. (BEITO, 2000). Em 1943, já havia em torno de 280.000 organizações sociais, cifra que superou 1.000 .000 no início da década de 1970, momento em que começou a se falar de terceiro setor (HALL, 2006)

Esse descompasso entre os fatos e o conceito evidencia o caráter "artificial" 
das denominações empregadas para designar o conjunto das organizações sociais: qualquer nomenclatura é uma escolha, a ser devidamente justificada à luz da compreensão da dinâmica da vida social. Na formulação norte-americana da noção de um "setor" próprio das organizações sociais foi decisiva a disponibilização, a partir de meados da década de 1960, de estatísticas governamentais sobre essas organizações. Com base nesses dados, intelectuais e ativistas, simpatizantes das mesmas, começaram a reivindicar o seu reconhecimento como um setor distinto do setor lucrativo e do governamental. Sua intenção era dar visibilidade e destaque à importância econômica e social de organizações criadas pela comunidade. A base empírica para a constituição do conceito de setor não lucrativo foram as estatísticas governamentais, baseadas no Internal Revenue Code. (HALL; BURKE, 2002)

A expressão terceiro setor foi utilizada pioneiramente por Amitai Etzioni, nos artigos "The Untapped Potential of the "Third Sector"' (1972) e "The Third Sector and Domestic Missions" (1973), nos quais desenvolveu a ideia da aproximação em curso entre as esferas pública e privada num movimento rumo a um terceiro setor, abrangendo iniciativas públicas de caráter não governamental, organizações voluntárias, fundações e parcerias entre os setores. Não se trata de uma proposta para o futuro, dizia Etzioni, e sim de um movimento real já existente no contexto norteamericano de então, materializado em iniciativas como o seguro de saúde, o crédito estudantil, o serviço postal, o projeto Apollo, da NASA, universidades e hospitais não lucrativos. Todos eram exemplos das vantagens do terceiro setor e da cooperação em contraposição à atuação isolada de um e outro setor. O terceiro setor poderia ser, conforme Etzioni (1973, p. 314), "a mais importante alternativa para as próximas décadas, não por substituição dos outros dois, mas por combinar e balancear seus importantes papéis".

A formulação inicial Etzioni carregava intuições que adquiriram relevância no debate posterior, como a do caráter público não estatal das organizações da sociedade civil, a necessidade de cooperação entre os setores e o tema do hibridismo das organizações. A partir de então o termo terceiro setor se difundiu em círculos acadêmicos e políticos. No mesmo período, em 1973, Theodore Levitt o utilizou o termo dentro da perspectiva neoclássica, para designar as iniciativas da sociedade que preenchiam lacunas do Estado e do mercado. Levitt identificou, em contraposição ao "velho terceiro setor", constituído por organizações clássicas (de caridade, comunitárias, clubes esportivos, sindicatos), o surgimento de um "novo terceiro setor", 
a partir da mobilização liderada por Martin Luther King, em 1963, que se utilizava de novas táticas de luta, afinadas com a contracultura. Em 1975, a nova terminologia foi utilizada no relatório da Comissão Filler, Giving in America: Toward a Stronger Voluntary Sector, que é considerado o marco referencial do setor não lucrativo norteamericano.

Embora a expressão terceiro setor tenha ganhado força em outros países, nos Estados Unidos acabou por predominar (na legislação e na literatura) a expressão setor não lucrativo, herdeira da tradição filantróprica, graças, sobretudo, à formulação teórica dos pesquisadores da Johns Hopkins University, sob coordenação de Lester Salomon. A teoria produzida por esses pesquisadores tornou-se padrão na pesquisa internacional. Com o selo da ONU e da UNESCO, pesquisas comparativas do terceiro setor passaram a ser realizadas em diferentes países por meio do "Johns Hopkins Comparative Nonprofit Sector Project", sob a liderança de Salamon e Anheier. (SALAMON et al, 2004) O projeto iniciou em 1991, avaliando a situação de 13 países do capitalismo central, entre os quais Estados Unidos, Alemanha, Suécia, França, Itália, Japão e Reino Unido. Nas rodadas seguintes foram incluídos novos países, que hoje abrange cerca de 45 países. O primeiro estudo sobre o Brasil é de autoria de Leila Landim (1993), intitulado "Defining the Nonprofit Sector: Brazil".

Hoje, é amplamente reconhecido pelos estudiosos que esse conceito-padrão de terceiro setor reflete uma experiência particular, norte-americana, e uma ótica particular, centrada no caráter não lucrativo. Sua universalização é indevida, não apenas porque desconsidera as características organizativas da sociedade civil em países com padrões sócio-culturais e trajetórias históricas muito distintas do caso norte-americano, mas também de países europeus caracterizados por um forte associativismo, notadamente a França e a Inglaterra. Além disso, o discurso do não lucrativo reproduz o viés da escolha racional; trata-se de um elemento do discurso prócapitalista. (CORRY, 2010; LAVILE, 2015; LORENTZEN, 2011)

O conceito de terceiro setor desenvolvido nos Estados Unidos e que é reproduzido no Brasil é fraco por três motivos principais. O primeiro é que seu foco está no não lucrativo, uma noção em si mesmo confusa. Na legislação norte-americana, o caráter não lucrativo expressa-se pela não distribuição de benefícios ou resultados aos participantes e dirigentes (esse critério exclui, por exemplo, cooperativas e organizações mutualistas). Porém, no senso comum formado em torno dessa expressão, frequentemente é considerado que organização não lucrativa é aquela que 
não gera superávit e não cobra pelos serviços prestados. O segundo motivo é seu vínculo com a noção de filantropia sob um viés conservador: o terceiro setor seria uma expressão da filantropia no sentido de caridade, de auxílio aos necessitados, o que não se aplica à maioria das organizações sociais. O terceiro é que esse conceito esconde a força transformadora da sociedade civil ao incorporar a ideia de que cabe às organizações sociais um papel residual, o de sanar falhas do mercado e do Estado.

Outra fragilidade a ser destacada na visão convencional é a reprodução acrítica de esquemas binários sobre o conjunto das organizações. A persistência da dicotomia público/privado - uma das dicotomias clássicas do pensamento político ocidental, derivada da filosofia grega e do direito romano - no pensamento político e jurídico brasileiro é um obstáculo ao reconhecimento do terceiro setor como um setor específico. Por conta desse esquema conceitual binário, a absoluta maioria dos estudos continua a caracterizar as organizações do terceiro setor como "privadas", colocando-as na gaveta conceitual dos entes mercantis e lucrativos. Na visão binária, não há três setores, apenas dois: o público (estatal) e o privado (cuja maior parcela é de empresas lucrativas e uma parcela menor de entidades não lucrativas). (FONTANA, 2018)

Uma breve referência aos estudos brasileiros ilustra esse esquema binário. $\mathrm{O}$ terceiro setor é composto por organizações sem fins lucrativos e não estatais (ARAÚJO, 2005); é o conjunto de pessoas jurídicas privadas de fins públicos, sem finalidade lucrativa, constituídas voluntariamente por particulares, auxiliares do Estado na persecução de atividades de conteúdo social relevante (MODESTO, 1998); compreende todas as ações do setor privado sem vínculo com o Estado e que também não distribuem os lucros auferidos (COELHO, 2000); é composto por organizações de natureza "privada" (sem o objetivo do lucro) dedicadas à consecução de objetivos sociais ou públicos, sem ser integrante do governo (PAES, 2006; BAZOLI, 2009; ARAÚJO, 2009; FALCONER, 1999); é um guarda-chuva que engloba organizações privadas que não dependem do Estado, não têm fins lucrativos (HUDSON, 1999; COELHO, 2002); abrange as entidades sem fins lucrativos (MEREGE; BARBOSA, 1998); é composto por organizações privadas, formais, autônomas, que se declaram com finalidade pública e sem fim lucrativo (CICONELLO, 2008).

Continuar utilizando o conceito fraco de terceiro setor implica em respaldar a perspectiva da caridade tradicional, substituindo o vocabulário da solidariedade democrática e da igualdade social pelo da solidariedade filantrópica e do auxílio aos 
excluídos. Ignora-se, assim, todo o debate das últimas décadas sobre a importância da sociedade civil como espaço de discussão e articulação das pautas transformadoras. A maioria dos estudos e das referências midiáticas sobre o terceiro setor no Brasil está amarrada a esse conceito fraco: ao falar em terceiro setor tem em mente setor não lucrativo. É imperioso revelar e desfazer esse contrabando.

\section{A QUESTÃO TERMINOLÓGICA: EXPRESSÕES ALTERNATIVAS AO TERCEIRO SETOR}

A discussão terminológica que envolve o tema não é de menor importância. Como se mostra a seguir, a escolha das palavras carrega sentidos e traz implicações. Cada termo tem vantagens e desvantagens.

\section{a) Setor não lucrativo}

O conceito-padrão difundido pelos estudos inspirados nos pesquisadores da Johns Hopkins consideram cinco critérios para inclusão no setor não-lucrativo: (i) formalizadas, institucionalizadas; (ii) privadas (estrutura não governamental); (iii) autogovernadas; (iv) sem finalidade lucrativa (não distribuição de resultados a dirigentes ou proprietários); e (v) voluntárias (com significativo envolvimento de trabalho voluntário). (ANHEIER; LIST, 2005, p. 182)

Esses critérios são restritivos e não contemplam, inclusive em países desenvolvidos, um leque considerável das organizações criadas e mantidas pela sociedade civil. A constituição formal desconhece as numerosas organizações informais de países da periferia capitalista, incluindo o Brasil. A finalidade não lucrativa exclui cooperativas e entidades mutualistas. O trabalho voluntário não se aplica às instituições baseadas no trabalho profissionalizado, como universidades comunitárias, hospitais, museus e tantas outras. Ademais, o emprego do termo privado evidencia a submissão à concepção dualista público/privado.

A adoção de tais parâmetros leva a tipologias dos setores econômicos pouco esclarecedoras, como as adotadas por órgãos governamentais brasileiros. O Cadastro Geral de Empresas do IBGE, por exemplo, divide os setores em: órgãos da administração pública, entidades empresariais e entidades sem fins lucrativos, em consonância com os parâmetros da International Standard Industrial Classification of all Economic Activities - ISIC (IBGE, 2018) O artificialismo desse tipo de classificação 
aparece, por exemplo, quando se observa a inclusão de empresas estatais e de entidades cooperativas no leque das entidades empresariais. Empresa é um termo atribuído cotidianamente a organizações privadas, e essa tipologia conduz ao entendimento de que entidades empresariais corresponde a setor privado. Segundo o entendimento aqui exposto, é de boa lógica socioeconômica e contribui para o entendimento dos cidadãos situar as empresas estatais no setor público e as cooperativas no terceiro setor.

\section{b) Setor filantrópico}

O termo filantropia carrega historicamente significados vinculados à ajuda aos necessitados. No linguajar religioso cristão, foi tomado como equivalente à caridade. No contexto norte-americano, o sentido foi ampliado: a filantropia veio a englobar tanto atos caritativos individuais quanto ações coletivas e de mútua ajuda, mas o peso maior sempre esteve nas ações caritativas. Ainda hoje, a literatura trabalha com a noção de que a filantropia é a ação voluntária em prol do bem comum, incluindo doação, serviço e associação voluntários. Na segunda metade do século XIX, as fundações inauguraram a filantropia científica, um viés que assinalou mudanças profundas e permanentes: a noção de filantropia orientada pela compaixão foi substituída pela ideia de filantropia voltada à eficiência, objetivando e mensurando resultados sociais (SIEVERS, 2010; PAYTON; MOODY, 2008).

Utilizar a terminologia de setor filantrópico é tomar a parte pelo todo: uma parcela menor das entidades da sociedade civil tem como razão de ser a busca de auxílio aos necessitados, mas isso de forma alguma explica a existência de um vasto conjunto de entidades brasileiras que se estruturam em torno de interesses públicos ou coletivos.

O vínculo da filantropia com o assistencialismo decorre de abundantes experiências históricas em que lideranças, partidos e organizações de camadas ricas ou médias valem-se de expedientes assistencialistas enquanto defendem modelos econômicos excludentes. Nos Estados Unidos foi criado o termo filantrocapitalismo para denominar a incongruência do modo de agir das megacorporações econômicas, que financiam ações sociais mediante suas fundações ao mesmo tempo em que lideram a defesa dos mecanismos de exclusão econômica e social da globalização. Certos segmentos da sociedade civil brasileira continuam se empenhando em dar um sentido renovado à filantropia, mas essa é uma batalha perdida, inclusive no campo 
legal. A legislação de assistência social já substitui, por exemplo, a figura jurídica das entidades de fins filantrópicos pela das entidades beneficentes de assistência social (Lei 12.101/2009).

\section{c) Setor do voluntariado}

Setor do voluntariado segue na mesma toada de não lucrativo e de filantrópico, ao identificar a especificidade do terceiro setor pela ação voluntária dos cidadãos e membros das organizações. Estudos internacionais sobre o voluntariado utilizam critérios como doação de tempo, doação de dinheiro e ajuda a desconhecidos. O relatório mundial World Giving Index 2018 (CHARITIES AID FOUNDATION, 2018) apresenta os seguintes dez países melhor situados: Indonésia, Austrália, Nova Zelândia, Estados Unidos, Irlanda, Singapura, Kenya, Myanmar e Bahrain. O Brasil aparece em $122^{\circ}$ lugar.

A força discursiva do voluntariado está no seu apelo aos nobres ideais do altruísmo. Os comportamentos benevolentes são apresentados como antídoto a um mundo cada vez mais egoísta e individualista. Além de ser um traço característico das mais diferentes religiões, esse apelo também é um elemento do discurso de diferentes formas de pensamento preocupadas com o bem comum. Entretanto, a retórica do voluntarismo é notadamente frágil. Sua debilidade principal está na visão conservadora que marca o discurso e a ação dos seus adeptos: ao respaldar modelos econômicos produtores de desigualdade, modelos que são os responsáveis pelos inéditos níveis de exclusão social em tempos de abundância de bens materiais, o apelo ao voluntariado aparece como um remédio inócuo e uma forma de acobertar as raízes dos problemas sociais. Com relação à ideia de um setor do voluntariado, a mesma se choca com o fato de que grande parte das organizações da sociedade civil se mantém com trabalho profissionalizado e recursos provenientes de parcerias com o setor público e privado.

A necessária crítica ao voluntarismo ingênuo não pode levar a desconsiderar o fundamental papel do altruísmo na vida humana. O altruísmo é um elemento indispensável à boa sociedade e um complemento da cooperação (BOWLES; GINTIS, 2013), mas lembrando que "uma boa sociedade se sustenta melhor com base em organizações de serviços mútuos que mediante o voluntariado". (ETZIONI, 2001, p. 32)

É preciso desvelar o papel ideológico do discurso voluntarista tradicional e reforçar um novo discurso do altruísmo vinculado ao terceiro setor: a base do terceiro setor é a cooperação (associativismo), mas o altruísmo (voluntariado) será sempre um aspecto 
altamente favorável à boa vida e à boa sociedade.

\section{d) Setor da sociedade civil}

Sociedade civil é um conceito que passou a ter grande aceitação e notoriedade política a partir da década de 1980, no contexto da queda dos regimes do Leste Europeu e da crise do Estado de Bem-Estar. Vinculado a ideias como esfera pública não-estatal, redes, associações e capital social, o conceito de sociedade civil condensou significados centrais à ideia de democracia participativa. Em lugar dos estados totalitários que controlam todos os espaços sociais ou dos welfare states centralizados que tendem a colonizá-los, com o eclipse das virtudes cívicas por conta dos direitos de cidadania, o novo imaginário político preconizava um Estado menos intervencionista na vida social e uma sociedade civil ativa, autônoma, com cidadãos ativos inseridos em instituições virtuosas, capazes de mediar o debate das grandes questões públicas e combinando a luta por direitos com as responsabilidades próprias do senso de cidadania. (LORENTZEN, 2011; BARBER, 2000; WALZER, 1992) A sociedade civil organizada é a parcela que se organiza, capaz de agir de forma política e de assumir serviços, mediante organizações e movimentos sociais.

A visão excessivamente otimista acerca da sociedade civil veio a ser objeto de contestação. Dos argumentos críticos, interessam aqui particularmente duas admoestações. Um é de que na prática há um estreito vínculo entre as organizações da sociedade e o aparato estatal, por conta de financiamento e de compromissos partilhados, de modo a haver uma integração de grupos civis na hierarquia sistêmica, como aponta Norberto Bobbio (1987). Outro é de que a sociedade civil não é um bloco homogêneo e sim um conjunto extremamente diversificado de instituições e organizações. Apesar do discurso otimista sobre a superioridade normativa e as virtudes democráticas da sociedade civil em contraposição ao Estado e mercado, estudos empíricos mostram que suas organizações frequentemente alinham-se às finalidades políticas dos países hegemônicos, servem de suporte a medidas de cunho neoliberal, têm pouca transparência e não favorecem a autêntica participação dos cidadãos. (MURPHY, 2011). Há grandes diferenças quanto aos valores proclamados e vivenciados pelas organizações sociais se se leva em conta a busca do bem comum. Não se pode equiparar, por exemplo, uma organização racista como a Klu Klux Klan ou de defesa do armamentismo como a National Rifle Association com entidades empenhadas na proteção de populações desassistidas, como os Médicos sem 
Fronteiras, ou de crédito para os pobres, como o Grameen Bank. Impõe-se evitar o discurso genérico sobre as virtudes da sociedade civil e observar a contribuição das organizações para a construção de valores democráticos. (ETZIONI, 2013)

Na maior parte das vezes, o termo sociedade civil é utilizado como contraponto ao Estado e ao mercado - e não a setor público e privado -, designando uma esfera da vida social, não um setor econômico. Sua utilização como setor, todavia, foi sugerida por Salomon e pesquisadores da Johns Hopkins, sem abrir mão das premissas do conceito de setor não lucrativo. Essa nomenclatura - setor da sociedade civil - carrega uma série de inconvenientes, sendo o principal o fato de sociedade civil - um termo utilizado pelos filósofos contratualistas a partir do século XVI - ter um conteúdo semântico que ultrapassa em muito o tema da tipologia das organizações. Bruce Sievers (2010) lembra que sociedade civil se refere a um certo modo de viver em sociedade e que historicamente envolveu sete elementos principais: filantropia, bem comum, estado de direito, instituições voluntárias, direitos individuais, livre expressão e tolerância.

Convém, por isso, tratar a sociedade civil como uma esfera da vida social e suas organizações como um setor, o terceiro setor.

\section{e) Economia social e solidária}

A economia social é uma vertente econômica, de origem europeia, que propõe uma abordagem alternativa à teoria padrão nonprit, norte-americana, do terceiro setor. Seu principal diferencial é o tratamento dado a organizações fundamentais na história do associativismo europeu que não se adequam ao critério nonprofit: cooperativas e entidades mutualistas. Para a economia social, as organizações cooperativas e mutualistas são expressões fundamentais da democracia econômica e da solidariedade social. Excluí-las (ou secundarizá-las) do conceito de terceiro setor, como faz a literatura norte-americana, evidencia que tal abordagem é particularista e não dá conta da diversidade organizacional em nível internacional.

Mais que (ou além de) uma teoria do terceiro setor, a economia social é uma teoria econômica, alternativa à economia neoclássica. Busca suas fontes na tradição milenar das associações humanas, como no Egito dos faraós, na Antiguidade grecolatina, na China Imperial, na América Pré-Colombiana e na Europa Medieval. Confere grande importância ao ideário sociopolítico do associativismo da fase inicial dos tempos modernos, especialmente do cooperativismo e mutualismo, por afirmar valores 
próprios de uma economia não-mercantil, valores como a prioridade da utilidade social em relação ao lucro, da solidariedade sobre o benefício individual, da cooperação sobre a competição.

Segundo Jaques Defourny (2009), há quatro formas jurídicas que merecem atenção especial dos economistas sociais: as cooperativas, as entidades mutualistas, as organizações associativas e as fundações. A noção de economia social não exclui a busca de lucro em moldes não capitalistas, mas sua atenção está voltada para as organizações que atendem quatro princípios: a) prioridade à prestação de serviços aos membros ou coletividade; b) autonomia de gestão; c) controle democrático pelos membros; d) na distribuição de excedentes, primazia das pessoas e do objeto social sobre o capital.

A União Europeia vem atribuindo notória importância à economia social em seus documentos e utiliza três critérios fundamentais para reconhecer uma empresa social ou entidade de economia social: (i) um objetivo social de interesse comum; (ii) o reinvestimento dos benefícios obtidos nesse objetivo; (iii) a governança democrática e participativa. (ULIONDO, 2016). Estatísticas sistematizadas pela Comitê Econômico e Social Europeu (2017) quantificam a importância da economia social em 28 países membros: cerca de 2,8 milhões de entidades e empresas geram 13,6 milhões de empregos remunerados (cerca $6,3 \%$ da população ativa) e possuem mais de 232 milhões de membros de cooperativas, sociedades mútuas e entidades, além de contar com mais de 82,8 milhões de voluntários.

A economia solidária é uma espécie de ramificação da economia social, que se expande a partir dos anos 1990, com foco nas atividades econômicas marcadas pela solidariedade, autonomia e gestão democrática. Além das formas clássicas de associativismo operário, parte importante dessa produção teórica aborda experiências em ambientes de periferia e de trabalhadores pobres (especialmente nos países do Sul do planeta), outra se volta para formas inovadoras de associativismo recente, impulsionadas pela exclusão laboral e pela sensibilidade a novas questões (ambientais, de gênero, étnicas e outras). (LAVILLE; GAIGER, 2009) A economia solidária radicaliza a abordagem da economia social visando construir uma visão econômica alternativa à economia neoclássica, acrescentando-lhe um componente político mais explícito: a reapropriação do patrimônio associativista implica em "repensar a economia mais além do mercado e o político mais além do Estado" como condição para renovar o enfoque da transformação social. (LAVILLE, 2015, p. 177) 
A economia social e solidária proporciona aportes fundamentais para o conceito forte de terceiro setor ao mostrar o vínculo que liga o associativismo e as organizações da sociedade atual com a tradição associativista: a cooperação, a solidariedade. Melhor do que entender a economia social ou a economia solidária como um setor (uma terminologia alternativa a terceiro setor) é tomá-las como uma perspectiva socioeconômica que realça a solidariedade. Sua contribuição é notável para repensar o significado do terceiro setor nos ambientes capitalistas atuais e prospectar a construção do futuro para além do capitalismo.

\section{O TERCEIRO SETOR, HERDEIRO DA TRADIÇÃO ASSOCIATIVA}

Os humanos temos uma longa tradição associativa, uma das principais manifestações da nossa natureza de animais sociais. Entre todas as espécies do planeta, destacamo-nos por ter em algo grau duas características básicas da sociabilidade: a ajuda mútua (cooperação) e a ajuda aos outros (altruísmo), intrincadas com a cultura e as instituições sociais. O neurocientista António Damásio (2018) argumenta que a orientação social dos humanos tem origens remotas e humildes: está nos organismos unicelulares, nas formas mais básicas de vida, há cerca de 4 bilhões de anos atrás. Nas bactérias, encontramos o fundo primordial da nossa interação social: sem qualquer estrutura ou sentimentos cerebrais, as bactérias colaboram entre si e rejeitam aquelas que não ajudam o grupo. Há cerca de 100 milhões de anos atrás, a evolução chegou a um novo momento, o dos insetos sociais, capazes de criar cidades, sistemas de governança e economias funcionais. Adiante, os mamíferos, com destaque para os primatas e os hominídeos (6 milhões de anos), revelam elevada capacidade de cooperar. O salto mais avançado foi dado pelos sapiens (100 a 200 mil anos), com habilidades notáveis e únicas.

Esse entendimento distingue o novo evolucionismo, que se consolidou a partir das investigações de Piotr Kropotkin, no início do século $X X$, o qual relê a teoria da evolução de Darwin, que havia sido apropriada pelo enfoque individualista do darwinismo social. Kropotkin apresentou fartas evidências empíricas de que a evolução não é presidida pela luta de cada indivíduo por sua sobrevivência, mas por uma combinação dos impulsos de luta pela sobrevivência e da ajuda mútua. Essa interpretação ganhou amplo reconhecimento. O biólogo e matemático Michael Nowak (2009) afirma que a pesquisa científica conduzida por essa diretriz levou a biologia a 
acrescentar aos dois princípios clássicos da teoria evolutiva - seleção e mutação - um terceiro princípio: a cooperação, indispensável para entender os aspectos criativos da evolução. Além da biologia evolutiva, esse fio da meada vem orientando pesquisas em campos da ciência como a psicologia evolutiva, a economia experimental, a teoria dos jugos, a sociologia, a antropologia cultural, as ciências da cognição e outros.

Segundo Kropotkin (2009, p. 22), "tanto a ajuda mútua quanto a luta de todos contra todos são uma lei da vida animal; mas, enquanto fator de evolução, a primeira tem provavelmente uma importância muito maior" na medida em que "favorece o desenvolvimento dos hábitos e características que asseguram a manutenção e a evolução da espécie, além de maior bem-estar e melhor qualidade de vida para o indivíduo com o menor dispêndio de energia". As primeiras formações sociais humanas foram bandos, tribos ou sociedades semelhantes às sociedades dos mamíferos superiores, evoluindo daí para os clãs, com aparição bem mais tarde da família. Os vestígios arqueológicos indicam que o homem primitivo se caracterizou pela forte solidariedade tribal, assentada no direito comum da tribo. Com a aparição das famílias separadas, um importante desenvolvimento cooperativo, existente em todos os continentes, foi a comunidade aldeã, constituída pela união de famílias de descendência comum e que possuíam um certo território em comum.

Cooperação e altruísmo andam juntos no processo evolutivo. O biólogo Edward Wilson (2013) afirma que a extensão do comportamento altruísta singulariza os humanos, notado nas mais diferentes sociedades em gestos como o cuidado aos doentes e idosos, apoio aos necessitados, sacrifício pelo grupo e até em favor de estranhos. Todas as pessoas normais são capazes de autêntico altruísmo. Trata-se de um impulso natural: "o altruísmo autêntico se baseia num instinto biológico pelo bem comum da tribo, posto em marcha pela seleção de grupo, em que grupos de altruístas da pré-história prevaleceram sobre grupos de indivíduos em desordem egoísta". (WILSON, 2013, p. 303)

A história das associações remonta ao Egito antigo, à Antiguidade greco-latina, à China Imperial, à América Pré-Colombiana e à Europa Medieval. Entre as formas organizativas da Idade Média destacam-se as cidades livres, em que parte da vida pública era definida em assembleias populares, e as corporações (guildas), caracterizadas pela ajuda fraterna, autoadministração, propriedade comum de bens e deveres sociais. Em alguns locais, as cidades organizaram-se como federações de corporações e de comunidades aldeãs. 
Nos tempos modernos, ampliou-se o leque de organizações. A sociedade moderna é fundamentalmente uma sociedade de organizações, considera Etzioni (1974, p. 7): "Nascemos em organizações, somos educados por organizações e quase todos nós passamos a vida a trabalhar para organizações", as quais são um meio mais eficiente de satisfazer as necessidades comuns que os agrupamentos menores, como a família, os amigos e as comunidades. Todavia, no caso do associativismo, sua afirmação deu-se às custas de embates com o Estado. Para afirmar sua autoridade, os estados nacionais empenharam-se em eliminar as instituições de cooperação medievais e controlar o associativismo nascente. Só o Estado e a Igreja podiam, por lei, cuidar de assuntos gerais. "A absorção de todas as funções sociais pelo Estado favoreceu necessariamente o desenvolvimento de um individualismo desenfreado e tacanho", diz Kropotkin (2009, p. 181), mas subsistiram por toda parte instituições comunais e foram criadas novas formas de cooperação, como sindicatos, associações, cooperativas, sociedades de amigos, clubes, irmandades, institutos, alianças - fato revelador de que os hábitos e costumes de ajuda mútua permanecem plenamente vivos.

Pode-se distinguir três momentos do associativismo moderno, segundo Laville (2015), que correspondem mais propriamente à realidade dos países europeus, mas guardam similaridades com o acontecido em outros países. Um primeiro momento compreende o período dos primórdios da Revolução Industrial até o início do século $X X$, em que se destaca a afirmação da solidariedade democrática pelo associativismo pioneiro. Enfrentando severos embates com forças estatais, cooperativas, entidades mutualistas, associações de luta pelos direitos das mulheres e de minorias afirmaram um sentido de solidariedade mediante a ajuda mútua, na luta por direitos para todos e de uma ordem econômica com predomínio do bem comum sobre o lucro. O segundo momento corresponde à expansão do Estado de Bem-Estar Social, nas primeiras décadas do século passado, em que a solidariedade foi delegada ao poder público. A solidariedade democrática deu lugar à solidariedade via ação estatal, um processo ambíguo em que o intervencionismo estatal marcou tanto o acesso a direitos como a tutela estatal sobre os cidadãos. O terceiro momento corresponde ao ressurgimento associacionista em meio às crises do welfare state e da ascensão e crise de seu contraponto ideológico, o neoliberalismo. O ressurgimento associacionista se manifesta em múltiplas formas: economia popular nos países do Sul, serviços de proximidade nos países do Norte, comércio justo, micro-finanças, moedas sociais e outros. Essas 
iniciativas atualizam as grandes questões da solidariedade democrática levantadas pelo associativismo pioneiro, ao endossar a defesa da sustentabilidade ambiental, de relações econômicas justas entre produtores e consumidores e de formas democráticas participativas. Por outro lado, há uma nova onda filantrópica, estimulada pelas corporações econômicas, que busca reconfigurar a filantropia, aplicando ao setor não lucrativo os mais modernos métodos do capitalismo.

Evocar a tradição associativa permite perceber que as organizações da sociedade civil de hoje têm em comum com as organizações de outros tempos o fundamento da sua razão de ser: são respostas coletivas a problemas e necessidades coletivas. Sua base fundamental é a cooperação, que é mais abrange que o altruísmo. Conforme Robert Axelrod (2010), o comportamento cooperativo é próprio não só pessoas dispostas a ajudar os outros sem expectativa de reciprocidade (o sentimento altruísta que move o voluntarismo), mas de individualistas esclarecidos cientes de que cooperar é frequentemente a melhor opção para atingir os interesses individuais. A distinção entre cooperação e altruísmo (que está longe de sustentar qualquer dualismo do tipo "bem x mal") proporciona uma fundamentação do terceiro setor com base em uma abordagem "realista" sobre o comportamento humano e a ação coletiva ao reconhecer que parte do comportamento colaborativo e da ação coletiva é explicável pelo interesse mútuo estrategicamente guiado.

Enquanto a tradição filantrópica sugere que o terceiro setor é capaz de cumprir tão-somente o papel residual de sanar falhas do mercado e do Estado, a tradição associativa sugere que as respostas coletivas são o melhor e único meio para enfrentar os grandes problemas dos dias atuais. O essencial do associativismo "radica no questionamento da concepção atomista do indivíduo pela experiência vivida da solidariedade recíproca", diz Laville (2015, p. 177). A reapropriação do associativismo é essencial para a afirmação do papel público do terceiro setor.

\section{O CONCEITO FORTE DE TERCEIRO SETOR E SEUS ENLACES TEÓRICOS}

O conceito forte de terceiro setor encontra apoio, portanto, na referência à milenar tradição associativa, ou seja, ao amplo e diversificado conjunto de formas de ação coletiva ao longo da história. A rigor, tendo em mente o viés cronológico, deverse-ia denominá-lo como "primeiro setor", visto que a esfera comunitária é muito anterior 
à esfera estatal e mercantil. Entretanto, levando em conta a quase impossibilidade de anular terminologias já consagradas, cabe insistir no fundamental: a existência de um âmbito específico (sociedade civil) na origem das organizações sociais distintas das estatais e privadas (terceiro setor).

O conceito forte de terceiro setor expressa-se na formulação sintética de conjunto das organizações da sociedade civil, que visam atender necessidades e resolver problemas públicos ou coletivos.

Propõe-se aqui quatro critérios para caracterizar as organizações de terceiro setor: (i) ser criada e mantida pela sociedade civil; (ii) ter autonomia frente órgãos estatais e empresas privadas; (iii) ter o objetivo de atender necessidade do público ou de uma coletividade; (iv) reinvestir o resultado econômico na organização ou distribuir coletivamente os resultados. Esses critérios operacionalizam o conceito forte do terceiro setor, pois são abrangentes e realçam a dimensão associativa mais que a altruísta. O primeiro assinala o caráter distintivo em relação ao mercado e ao Estado: as organizações do terceiro setor são próprias da terceira esfera social, a comunidade ou sociedade civil. $O$ segundo destaca sua autonomia frente à esfera estatal e mercantil: mesmo que os limites entre as esferas sejam pouco nítidos, com múltiplas influências cruzadas e que parcela significativa das organizações da sociedade civil receba financiamento de empresas privadas e órgãos públicos (o que limita a sua liberdade de ação), o pertencimento ao terceiro setor supõe que a entidade tenha certo grau de autonomia. O terceiro critério inclui e coloca em um mesmo patamar as organizações voltadas ao benefício de seus associados (cooperativas e mutualidades) e aquelas voltadas ao benefício mais geral da sociedade. O quarto critério assinala que a marca distintiva do terceiro setor em relação ao setor privado não reside na geração de resultados: reside na apropriação ou distribuição dos mesmos. Em entidades do terceiro setor não há apropriação privada: as cooperativas e entidades mutualistas destinam os resultados ao conjunto dos associados; nas demais, os resultados são reinvestidos na missão da organização.

Por outro lado, esses critérios não incluem a formalidade (muitas organizações da sociedade civil não têm registro formal), nem a governança democrática, um requerimento enfatizado pela economia social. Embora desejável, a inclusão deste critério exclui parte significativa das organizações da sociedade civil brasileiras, como aquelas de caráter confessional, que não têm (ainda) uma conformação democrática e mesmo assim prestam serviços de interesse público. Pode-se objetar que o critério da 
governança democrática exclui as organizações com valores e finalidades não democráticas (como as de defesa do armamentismo, de grupos privilegiados e segregacionistas, racistas). A resposta a esta objeção já foi indicada acima: a sociedade civil é uma esfera em que se manifestam as contradições próprias dos grupamentos sociais. Não é uma esfera virtuosa no seu todo; o modus operandi de parte das entidades fortalece a democracia, o de outras a fragiliza. Henry Tam (1998) acentua que a ação de grupos comunitários comprometidos com o bem comum é vital para que a sociedade civil dê uma contribuição efetiva para a qualidade de vida dos cidadãos.

Os critérios do conceito forte de terceiro setor são pertinentes para abranger a pluralidade das mais de 500 mil organizações formais da sociedade civil brasileira (segundo dados do Cadastro Central de Empresas de 2010), abarcando: organizações não governamentais, entidades sem fins lucrativos, associações, fundações, universidades comunitárias, escolas comunitárias, bancos comunitários, rádios e TVs comunitárias, entidades religiosas, culturais e artísticas, cooperativas, entidades mutualistas, sindicatos, partidos políticos, clubes esportivos, condomínios e outras denominações. (SCHMIDT, 2017)

O fortalecimento do conceito forte de terceiro setor no contexto das teorias da ação coletiva requer o diálogo com correntes de pensamento que compreendem a dinâmica da vida social para além da dicotomia público/privado, reconhecendo a importância da comunidade ou sociedade civil. Destacam-se especialmente o comunitarismo, as teorias da cooperação, as teorias da sociedade civil, as teorias do capital social, as teorias dos bens comuns e a economia do compartilhamento.

O comunitarismo rompe com a compreensão dualista público/privado da vida social. Para Etzioni (2007), múltiplos fenômenos sociais estão para além do poder estatal ou do interesse pelo lucro, e parte importante das soluções de problemas humanos é desenvolvida no âmbito da família, da vizinhança e das redes comunitárias. A comunidade é a esfera da criação e recriação de valores, os quais são elementos fundamentais para a legitimação das organizações, das políticas e do funcionamento do mercado. Os valores são um vetor de análise necessário das próprias organizações da sociedade civil: certas organizações são muito mais fundamentais que outras para a construção de valores de bem comum.

As teorias da sociedade civil, apesar de em boa parte não se descolarem do dualismo público/privado, destacam-se pela defesa da descentralização do poder, da 
participação popular, do papel democrático dos movimentos e organizações sociais. O conceito de esfera pública ampliada, proposto por Jürgen Habermas, teve grande impacto no pensamento filosófico para a compreensão dos vínculos e cisões entre o Estado e a sociedade civil, inspirando variadas experiências de participação cidadã. (VIEIRA, 2001)

As teorias da cooperação solapam a visão egoísta do ser humano (premissa do liberalismo e do capitalismo) ao trazer evidências de vários campos do conhecimento sobre a nossa índole natural para a cooperação e o altruísmo. (BENKLER, 2011). Ao longo dos tempos mudam as formas, mas a habilidade e a disposição para cooperar e ajudar é permanente, traço que levou os humanos à condição de espécie dominante do planeta. Em tempos de globalização, de internet, de terceira ou quarta revolução industrial, é preciso ficar atento às novas expressões colaborativas que se repõe por toda parte.

O reconhecimento da importância dos aspectos psicossociais e da tradição cultural para a compreensão da política e da economia é um dos méritos das teorias do capital social. A partir da pesquisa de Robert Putnam (2006) sobre a experiência italiana difundiu-se internacionalmente o entendimento de que aspectos ligados ao cotidiano e à vida comunitária, como confiança interpessoal e associativismo, são decisivos na ação coletiva e tem fortes repercussões no desenvolvimento econômico e na ação política.

A teoria dos bens comuns soma-se à argumentação comunitarista contrária ao dualismo público/privado. Apoiada no estudo de experiências colaborativas em diferentes continentes, Elinor Ostrom (2011) mostra que é indevida a lógica binária utilizada nas políticas públicas de buscar as soluções para os problemas comuns em medidas governamentais ou na iniciativa privada. Seja no uso de terras, da água ou da pesca, algumas melhores soluções foram/são construídas comunitariamente, sendo, por isso, necessário que em cada caso se analise a pertinência de optar pela ação governamental, privada ou comunitária.

A economia do compartilhamento (ou economia colaborativa) contém interessantes abordagens sobre novas formas de colaboração em tempos de internet. O desenvolvimento tecnológico vem favorecendo a emergência de um amplo conjunto de manifestações colaborativas no campo do trabalho, da cultura, das artes, tendo por base a imensa a facilidade de conexões sociais possibilitada pela internet, meios de comunicação e meios de transporte. Autores como Jeremy Rifkin (2016) e Rachel 
Botsman (2011) ilustram a tese com exemplos como Linux, Wikipedia, sistemas de distribuição de automóveis e bicicletas, aluguel de brinquedos infantis, filmes, livros e energia solar, mercados de roupas e produtos diversificados, além de estilos de vida colaborativos que incluem espaços para coworking, crowdfunding e moedas sociais. Rifkin sugere a tese de que estamos em transição da economia capitalista de mercado (com o predomínio do trabalho individualizado, da propriedade privada e da posse dos bens) para a economia do compartilhamento (de trabalho colaborativo, governança dos bens comuns e acesso aos bens).

Por derradeiro, a economia social e solidária (e congêneres: economia popular, plural, feminista, moral), por seus aportes a uma concepção humanista da economia, em contraposição à visão neoclássica dominante. Essa vertente, fortemente crítica ao capitalismo, proporciona elementos mais diretos para a leitura do terceiro setor à luz da tradição associativa aqui empreendida. A economia solidária tem especial relevância para contextos da periferia capitalista, como o Brasil. (CATTANI et al., 2009)

No diálogo com essas respeitáveis perspectivas teóricas, o conceito forte de terceiro setor pode se estabelecer como a concepção que melhor expressa a vitalidade da sociedade civil.

\section{CONSIDERAÇÕES FINAIS}

A utilização do conceito fraco de terceiro setor, radicado na experiência histórica do nonprofit sector norte-americano, é um obstáculo para o reconhecimento teórico e político acerca do relevante papel das organizações da sociedade civil. Deriva desse conceito fraco uma série de ambiguidades, como a caracterização das organizações da sociedade civil com base na adjetivação de não lucrativas ou com fins não econômicos, presente na legislação brasileira. E mais grave: o papel conferido ao terceiro setor é secundário, residual, o de preencher falhas do Estado e do mercado.

A construção de um conceito forte tem dois requisitos principais: a elucidação das inconsistências da noção do nonprofit sector, focada no não lucrativo e contrabandeada no mais das vezes sob o termo terceiro setor; e o balizamento do terceiro setor em bases robustas, condizentes com a melhor reflexão acadêmica atual.

$O$ conceito forte de terceiro setor explicitado ao longo do texto assenta-se em duas premissas centrais. A primeira é a de que o esse setor é manifestação de características inerentes à condição humana e sempre presentes em qualquer contexto 
social: a cooperação e o altruísmo. Sob o viés da tradição associativa, o terceiro setor está em linha de continuidade com as variadas formas de colaboração criadas ao longo do tempo pelos humanos para resolver problemas comuns. As organizações da sociedade civil de hoje são as herdeiras da milenar tradição associativa. A segunda premissa é a de que o terceiro setor é próprio de uma esfera social específica comunidade ou sociedade civil -, e suas organizações seguem uma lógica distinta da do setor estatal e do privado. Atribuir-Ihe um papel residual é próprio de preconceitos privatistas ou estatistas ainda arraigados na cultura política e jurídica do Ocidente.

Este conceito forte encontra respaldo em respeitáveis formulações teóricas dos dias atuais, entre as quais: o pensamento comunitarista, as teorias da sociedade civil, as teorias do capital social, as teorias da cooperação, as teorias dos bens comuns, as teorias da economia do compartilhamento e as teorias da economia social e solidária. Destaca-se nesse conjunto a obra comunitarista, cuja arquitetura conceitual tem importância toda especial ao distinguir três esferas na vida social (Estado, comunidade e mercado), vinculando o terceiro setor à esfera da comunidade e enaltecendo a centralidade da cooperação (mais que o altruísmo) na resolução de problemas comuns. O comunitarismo fornece um conjunto de antídotos ao conceito fraco e o cimento teórico para o conceito forte de terceiro setor. 


\section{REFERÊNCIAS}

ANHEIER, Helmut; LIST, Regina. A dictionary of civil society, philanthropy and the non-profit sector. London, New York: Routlege, 2005.

ARAÚJO, Osório Cavalcante. Contabilidade para organizações do terceiro setor. São Paulo: Atlas, 2009.

BARBER, Benjamin. Un lugar para todos: como fortalecer la democracia y la sociedad civil. Barcelona: Paidós Ibérica, 2000.

BAZOLI, Tiago N. Terceiro setor: parcerias com o Estado à luz do desenvolvimento social sustentável. Saúde em Destaque, Londrina:, 2009.

BENKLER, Yochai. The penguin and the Leviathan: how cooperation triumphs over self-interest. New York: Crown Business, 2011.

BOBBIO, Norberto. Estado, governo, sociedade: para uma teoria geral da política. Rio de Janeiro: Paz e Terra, 1987.

BOTSMAN, Rachel; ROGERS, Roo. O que é meu é seu: como o consumo colaborativo vai mudar o nosso mundo. Porto Alegre: Bookman, 2011.

BOWLES, Samuel; GINTIS, Herber. A cooperative species: human reciprocity and its evolution. Princeton: Princeton University Press, 2013.

CATTANI, Antonio D. et al. Dicionário internacional da outra economia. Coimbra: Almedina, 2009.

CHARITIES AID FOUNDATION. World Giving Index 2018. Kings Hill: Charities Aid Foundation, 2018.

CICONELLO, Alexandre. O Conceito Legal de Público no chamado "Terceiro Setor". Disponível em: http://www.abong.org.br/novosite/download/conceito_legal.pdf. Acesso em 12/02/2019.

COELHO, Simone de Castro Tavares. Terceiro setor: um estudo comparado entre Brasil e Estados Unidos. 2. ed. São Paulo: Senac, 2002.

COHEN, Jean; ARATO, Andrew. Sociedad civil y teoría política. México: Fondo de Cultura Económica, 2000.

CORRY, Olaf. Defining and theorizing the third sector. In: TAYLOR, Rupert. (ed.). Third sector research. New York: Springer Science+Business Media, 2011, p. 11-20.

DAMÁSIO, António. A estranha ordem das coisas: a vida, os sentimentos e as culturas humanas. Lisboa: Círculo de Leitores, 2018. 
ETZIONI, Amitai. Análise comparativa de organizações complexas: sobre o poder, o engajamento e seus correlatos. Rio de Janeiro: Zahar, São Paulo: Edusp, 1974.

ETZIONI, Amitai. La dimensión moral: hacia una nueva economia. Madrid: Astor Juvenil Palabra, 2007.

ETZIONI, Amitai. La tercera vía hacia una buena sociedad: propuestas desde el comunitarismo. Madrid: Trotta, 2001.

ETZIONI, Amitai. Law in civil society, good society, and the prescriptive state. Chicago-Kent Law Review, v. 75, n. 2, p. 1-24, 2013.

FALCONER, A. P. A promessa do terceiro setor: um estudo sobre a construção do papel das organizações sem fins lucrativos e do seu campo de gestão. Dissertação (Mestrado em Administração). Universidade de São Paulo, São Paulo, 1999.

FONTANA, Eliane. Terceiro setor e cooperação pública: proposições para um marco conceitual das organizações da sociedade civil na perspectiva comunitarista. Tese de doutorado. Programa de Pós-Graduação em Direito. Universidade de Santa Cruz do Sul, 2018.

HALL, Peter D. A historical overview of philanthropy, voluntary associations, and nonprofit organizations in the United States, 1600-2000. In: POWELL, W.;

STEINBERG, R. The nonprofit sector: a research handbook. New Haven \& London: Yale Univesity Press, 2006, p. 32-65.

HALL, Peter D.; BURKE, Colin. Historical statistics of the United States chapter on voluntary, nonprofit, and religious entities and activities: underlying concepts, concerns, and opportunities. Harvard University, 2002. Disponível em:

http://cpl.hks.harvard.edu/files/cpl/files/workingpaper_14.pdf?m=1440169409. Acesso em: 10 jan. 2019.

HUDSON, Mike. Administrando organizações do Terceiro Setor: o desafio de administrar sem receita. São Paulo: Makron Books, 1999.

INSTITUTO BRASILEIRO DE GEOGRAFIA E ESTATÍSTICA - IBGE. Estatísticas do cadastro central de empresas 2016. Rio de Janeiro: IBGE, 2018.

JEFFRIES, Vincent (ed.). The Palgrave handbook of altruism, morality, and social solidarity. New York: Palgrave Macmillan, 2014.

LANDIM, Leilah. Defining the nonprofit sector: Brazil. Working Papers of the Johns Hopkins Comparative Nonprofit Sector Project, no. 9, edited by Lester M. Salamon and Helmut K. Anheier. Baltimore: The Johns Hopkins Institute for Policy Studies, 1993.

LAVILLE, Jean-Louis. Asociar-se para el bien común: tercer sector, economía social y economía solidaria. Barcelona: Icaria, 2015.

LORENTZEN, Häkon. Sector labels. In: TAYLOR, Rupert (ed.). Third sector research. 
New York: Springer, 2011, p. 21-35.

MARQUES; B. A. et al. Terceiro setor: panorama das tendências de 1998 a 2013 por meio de um estudo bibliométrico. Revista Cont. UEM, Paraná, v. 34, n. 2, p. 71-89 mai./ago. 2015.

MEREGE, L. C.; BARBOSA, M. N. L. $3^{\circ}$ Setor: reflexões sobre o marco legal. São Paulo: FVG, 1998.

MODESTO, Paulo. Reforma do marco legal do terceiro setor no Brasil. Revista de Direito Administrativo, Rio de Janeiro, n. 214, p. 55-68, out./dez. 1998.

MURPHY, Jonathan. The dark side. In: TAYLOR, Rupert. (ed.). Third sector research. New York: Springer Science+Business Media, 2011, p. 253-268.

NOWAK, Michel; HIGHFIELD, Roger. Supercooperators: altruism, evolution and why we need each other to succeed. New York: Free Press, 2011.

OSTROM, Elinor. El gobierno de los bienes comunes: la evolución de las acciones de acción coletiva. México: Fondo de Cultura Económica, 2011.

PAES, José Eduardo Sabo. Fundações e entidades de interesse social: aspectos jurídicos, administrativos, contábeis e tributários. 5. ed. rev., atual. e ampl. de acordo com a Lei n 10.406, de 10.1.2002. Brasília: Brasília Jurídica, 2004, p. 98/99.

PUTNAM, Robert. Comunidade e democracia: a experiência da Itália Moderna. São Paulo: FGV Editora, 2006.

RIFKIN, Jeremy. Sociedade com custo marginal zero: a internet das coisas, os bens comuns colaborativos e o eclipse do capitalismo. São Paulo: M. Books, 2016.

SALAMON et al. Global civil society: dimensions of the nonprofit sector. v. 2. Bloomfield: Kumarian Press, 2004.

SCHMIDT, João P. Universidades comunitárias e terceiro setor: fundamentos comunitaristas da cooperação pública. Santa Cruz do Sul: Edunisc, 2017.

SIEVERS, Bruce. Civil society, philanthropy, and the fate of the commons. Lebanon NH: University Press of New England, 2010.

TAM, Henry. Communitarianism: a new agenda for politics and citizenship. New York: New York University Press, 1998.

TOMASELLO, Michael. Why we cooperate. Cambridge, London: The MIT Press, 2009.

ULIONDO, Igone A. Otro enfoque para las entidades de la economía social. CIRIECEspaña - Revista Jurídica, n. 28, p. 1-36, 2016.

UNIÃO EUROPEIA - Comité Económico e Social. Evolução recente da economia social na União Europeia - síntese. União Europeia, 2017. 
VIEIRA, Liszt. Os argonautas da cidadania: A sociedade civil na globalização. Rio de Janeiro: Record, 2001.

WALZER, Michael. The civil society argument. In: MOUFFE, Chantal (ed.)

Dimensions of radical democracy: pluralism, citizenship and community. London: Verso, 1992.

Recebido em 08/06/2019 Aprovado em 18/04/2021 Received in 08/06/2019 Approved in 18/04/2021 